DOI: http://dx.doi.org/10.18309/anp.v1i51.1297

\title{
LITERATURA E DIREITOS HUMANOS EM É ISTO UM HOMEM? DE PRIMO LEVI
}

\section{LITERATURE AND HUMAN RIGHTS IN IF THIS A MAN BY PRIMO LEVI}

\author{
Thaís Helena de Barros Neves Cavalcanti \\ Universidade de São Paulo, São Paulo, São Paulo, Brasil \\ thais.cavalcanti@gmail.com
}

\begin{abstract}
Resumo: A proposta deste artigo é discutir as relações entre literatura e direitos humanos a partir das ideias de Antonio Candido, no texto $O$ direito à literatura, e da obra de Primo Levi, $E$ isto um homem?, publicada como testemunho da experiência nos campos de concentração durante a Segunda Guerra Mundial. A análise, em um primeiro momento, concentra-se na presença do texto literário, mais especificamente a Divina Comédia de Dante Alighieri, na recordação do prisioneiro italiano, de modo a compreender a força humanizadora da literatura que se impõe como fundamental ainda em tempos sombrios. Nesse sentido, não apenas o conteúdo do discurso, mas também a forma engendrada pelo poeta, são vistos como significativos no processo de humanização colocado em marcha pela literatura. A seguir é tratada a questão da promoção dos direitos humanos pela obra literária do próprio Levi, que denuncia os horrores aos quais milhares de homens foram submetidos, em uma tentativa de impedir que fatos como esse se repitam nas gerações futuras.
\end{abstract}

Palavras-chave: Antonio Candido; Primo Levi; Direitos Humanos; Dante Alighieri

\begin{abstract}
The purpose of this paper is to discuss the relationship between literature and human rights considering Antonio Candido's ideas in the text $O$ direito à literatura (The right to literature) and the work of Primo Levi, Survival in Auschwitz: If this is a Man, published as a testimony of the experience in the concentration camps during the World War II. The analysis initially focuses on the presence of the literary text, specifically the Divine Comedy of Dante Alighieri, in the mind of the Italian prisoner, in order to understand the humanizing power of literature, which is fundamental even in dark times. Not only the content of the speech, but also the form engendered by the poet are seen as significant in the humanization process set in motion by literature. The paper will also examine the issue of promotion of human rights by the literary work of Levi, that denounces the horrors to which thousands of men underwent, in an attempt to prevent events like this from recurring in future generations.
\end{abstract}

Keywords: Antonio Candido; Primo Levi; Human Rights; Dante Alighieri 


\section{Introdução}

Quando no inverno de 1945, os alemães, encurralados pelos soviéticos, forçaram dezenas de milhares de prisioneiros de Auschwitz a seguirem a pé por $56 \mathrm{~km}$ até Wodzislaw, no episódio conhecido como Marcha da Morte, Primo Levi estava internado com escarlatina na enfermaria do campo de concentração. A doença impediu-o de seguir viagem e deixou-o à própria sorte com os outros companheiros enfermos até a chegada das tropas soviéticas nove dias depois. Isso faz de Primo Levi um duplo sobrevivente, dos campos de concentração e dos fuzilamentos ocorridos nas marchas até os campos em território alemão.

Antes de ser capturado, aos 24 anos, Levi trabalhava como químico, tendo conseguido seu diploma apesar das leis raciais que entraram em vigor na Itália em 1938. Quando as forças armadas alemãs ocuparam o norte e o centro da Itália em 1943, Levi refugiou-se nas montanhas com os partigiani onde foi encontrado e preso pela milícia fascista e enviado ao campo de concentração de Carpi-Fòssoli. Em fevereiro do ano seguinte, os alemães assumiram o controle do campo em Modena e transferiram Levi e outros prisioneiros para o campo de Monowitz, no complexo de Auschwitz, onde o italiano ficaria até a libertação em 1945.

Após sair de Auschwitz, Levi vive por alguns meses em Katowice, um campo soviético de trânsito, onde trabalha como enfermeiro. A viagem de volta para casa é narrada na sua obra $A$ trégua, de 1963.

Dois anos após a libertação de Auschwitz, o jovem italiano publica seu primeiro livro, É isto um homem? (1947), escrito na urgência de contar ao mundo todo o horror vivido no Lager. Primo Levi afirma que a obra "doveva essere un atto d'accusa - non a scopo di provocare una rappresaglia, una vendetta, una punizione -, ma sempre una testimonianza" (LEVI apud CEREJA, 1989, p. 296). O livro, no entanto, não contém um discurso de ódio direcionado aos oficiais da $S S$ (Schutzstaffel, a organização paramilitar ligada ao Partido Nazista), nem mesmo ao governo alemão, mantendo uma linguagem sempre bastante sóbria e enxuta. Daí talvez a falta de sucesso imediato.

A obra pertence certamente ao que ficou conhecido a partir dos anos 70 por literatura de testemunho. Alfredo Bosi oferece uma definição clara e concisa sobre esse tipo de literatura, ao situá-la na intersecção de memórias e engajamento. O testemunho não pode ser considerado nem um trabalho de documentação histórica nem pura ficção (BOSI, 2002, p.180). Isso porque por um lado o autor busca escrever um texto que revele uma experiência coletiva a partir de fatos objetivos, por outro, ele sempre será uma testemunha individual partindo de um olhar subjetivo. Ao falar sobre literatura e engajamento em um ensaio publicado na revista Clima em 1941, Antonio Candido afirma que o grande papel da arte é ser "testemunha imperecível do sofrimento humano e de sua trágica grandeza" (CANDIDO, 1941b, p. 76).

A proposta deste artigo é investigar as relações entre literatura e direitos humanos na obra do escritor italiano, mais especificamente no livro $E$ isto um homem? (1947), partindo das reflexões feitas por Antonio Candido em seu texto $O$ direito à literatura (1988). As duas questões que se pretende enfrentar são estas: como pode ser interpretada a presença dos versos da Divina Comédia na memória de Primo Levi durante sua experiência no campo de concentração nazista e qual o papel de sua obra na promoção dos direitos humanos após a Shoá.

\section{A literatura dentro do campo}

Para abordar a primeira questão, irei recorrer à argumentação de Antonio Candido sobre a relação entre literatura e direitos humanos. Candido serve-se da distinção feita pelo 
sociólogo francês Louis-Joseph Lebret entre "bens compressíveis" e "bens incompressíveis". Os bens compressíveis são aqueles supérfluos, como os enfeites e os cosméticos. Os incompressíveis, por sua vez, são os bens dos quais dependem a sobrevivência e a dignidade humana, como os alimentos, a moradia, a literatura e as artes em geral.

Para justificar a inclusão da literatura entre os bens incompressíveis, Candido lembra que não há sociedade na qual não esteja presente alguma forma de fabulação, de manifestação ficcional e que ninguém é capaz de passar um dia inteiro sem contato com esse tipo de criação. Por satisfazer a essa necessidade de fabulação, podemos dizer que a literatura constitui uma necessidade profunda e universal do ser humano. Candido afirma ainda que a obra literária tem um poder humanizador. Como humanização o crítico entende

o processo que confirma no homem aqueles traços que reputamos essenciais, como o exercício da reflexão, a aquisição do saber, a boa disposição para com o próximo, o afinamento das emoções, a capacidade de penetrar nos problemas da vida, o senso da beleza, a percepção da complexidade do mundo e dos seres, o cultivo do humor (CANDIDO, 1995, p.180).

Desde a sua participação na revista Clima, no início dos anos 40, Candido deixa clara sua posição em relação à literatura, considerando-a como uma necessidade fundamental do ser humano. A literatura não pode ser compreendida como supérfluo justamente porque está presente mesmo nos tempos mais sombrios:

\footnotetext{
O mundo experimenta, sob o signo da catástrofe, uma das crises mais angustiosas por que tem passado. [...] E enquanto todos se crispam diante dos fatos que decidem a sorte do homem, qual o valor da obra literária, e qual atitude a se tomar em relação a ela? A sua justificativa está em afirmar, até onde lhe for possível, a consciência do indivíduo diante da tragédia, como manifestação permanente da dignidade humana. Se, portanto, ela continua a existir apesar de tudo, é porque há razão e há necessidade da sua existência. (CANDIDO, 1941a, p. 108)
}

A partir dessas considerações, interessa-me analisar um capítulo específico do livro $E$ isto um homem, intitulado $O$ canto de Ulisses. Neste capítulo Levi narra um momento que passou com Jean, um jovem prisioneiro francês que tinha a função de Pikolo.

Pikolo era o nome da função de assistente do Kapo, que por sua vez era um prisioneiro supervisor dos trabalhos forçados. Ao longo do livro, Levi algumas vezes reflete sobre a hierarquia entre os prisioneiros e a relação ambígua que alguns deles mantinham dentro do campo, como modo de garantir a própria sobrevivência, cooperando com os nazistas para livrarem-se do trabalho pesado e da morte. O resultado disso seria uma estrutura extremamente complexa, pensada estrategicamente para confundir oprimidos e opressores. Essa reflexão irá resultar no conceito de zona grigia (zona cinzenta) formulado por Levi na sua obra I sommersi e i salvati (1986) e depois largamente utilizado na política italiana para referir-se à complexa dinâmica das relações de poder.

Jean entra na cisterna onde alguns prisioneiros estão trabalhando e chama Levi para ir buscar a sopa com ele. Para Levi, buscar a sopa representa um alívio, cerca de uma hora caminhando livre dos trabalhos forçados. É Jean quem chama a sua atenção para o fato de que os dois deveriam, sem pressa, aproveitar ao máximo essa pausa: "Tu es fou de marcher si vite. On a les temps, tu sais" (LEVI, 1988, p. 114). No caminho, Jean explicita sua vontade de aprender italiano, e Levi começa a ensinar-lhe algumas palavras de sua língua materna. Surge na mente do prisioneiro italiano, sem que ele possa explicar, alguns versos do Canto XXVI do Inferno da Divina Comédia: “...o canto de Ulisses. Quem sabe como e por que veio-me à memória, mas não temos tempo para escolher, esta hora já não é mais uma hora. Se Jean é inteligente, vai compreender" (LEVI, 1988, p. 114). 
Antes de continuar, é preciso abrir um parêntese para explicar o que acontece no canto citado por Primo Levi, um dos episódios mais famosos de toda a Divina Comédia. Dante e seu guia Virgílio chegam à oitava bolgia do oitavo cerchio do inferno, lugar destinado aos conselheiros fraudulentos, quando o poeta florentino avista uma dupla chama que envolve as almas do herói grego Ulisses e de seu companheiro Diómedes. Ulisses está condenado àquela pena por dois conselhos que levaram à morte muitos homens: o primeiro foi a construção do cavalo de Troia, conforme narrado na Ilíada. O segundo ocorreu ao retorno de Ulisses da ilha onde vivia Circe, a feiticeira que transformou seus companheiros em porcos e, mais tarde, desfez o encanto. Ao deixar a ilha, o herói decide navegar para além do limite estabelecido pelas colunas de Hércules. Ultrapassar as colunas deixadas por Hércules significava ir além do que era permitido ao homem conhecer ["acciò che l'uom più oltre non si metta ${ }^{1}$ " (ALIGHIERI, 2012, p. 785)]. Para cumprir esse feito, Ulisses precisa convencer a tripulação, preocupada com o castigo das divindades. O herói então profere o seguinte discurso: "Considerate la vostra semenza:/ fatti non foste a viver come bruti,/ ma per seguir virtute e canoscenza"2 (ALIGHIERI, 2012, p. 788-789). Os companheiros de viagem aceitam a ideia de Ulisses e, após cruzar as ditas colunas, acabam sendo engolidos pelo mar. e incoerentes:

Levi esforça-se por lembrar-se de todo o Canto e o resultado são alguns versos soltos

[...] e depois de 'quando'? Nada. Um buraco na memória. 'Antes que a houvesse Eneias conhecido'. Mais um buraco. Vem à tona algum fragmento inaproveitável: 'nem a extremada velhice de meu pai, nem mesmo o amor de Penélope ansiosa e apaixonada...' (Será que está certo?). (LEVI, 1988, p. 117)

Candido afirma que a literatura atua sobre o ouvinte/leitor não apenas pela mensagem que ela transmite, mas também pela sua construção. A forma literária, segundo Candido, promoveria uma ordenação do caos e seria o primeiro fator de humanização, pois nos possibilita organizar nossa mente e nossos sentimentos. Por isso Primo Levi esforça-se tanto por lembrar os versos de Dante em sua integridade. Não basta para ele apenas a mensagem do poeta, mas o modo como ele construiu o seu poema: "Eu renunciaria à minha ração de sopa para poder ligar 'non ne avevo alcuna' com os versos finais" (LEVI, 1988, p. 117). A força da palavra organizada é fundamental para assegurar o efeito da mensagem. A forma do poema permite que o significado ganhe força e os dois, forma e conteúdo, constituem um par indissolúvel, capaz de aumentar o poder de pensar e de sentir do ouvinte/leitor. Nesse sentido, a memória com seu poder ordenador e estruturante exerce um papel fundamental na sobrevivência do indivíduo e do grupo, na resistência ao aniquilamento posto em execução nos campos nazistas. A tentativa de lembrar-se do poema que sabia de cor é um ato de resistência.

Em um determinado momento do texto, Levi diz:

Cuidado, Pikolo, abre os ouvidos e a mente, eu preciso que compreendas ${ }^{3}$ : considerate la vostra semenza/fatti non foste a viver come bruti/ ma per seguir virtute e canoscenza. É como se eu também ouvisse isso pela primeira vez: como um toque de alvorada, como a voz de Deus. Por um momento, esqueci quem sou e onde estou.

\footnotetext{
1 "Para que o homem mais além não tente". Trad. Italo Eugenio Mauro. (ALIGHIERI, 2008, p. 179).

2 "Considerai a vossa procedência:/não fostes feitos para viver quais brutos/mas pra buscar virtude e sapiência". Trad. Italo Eugenio Mauro. (ALIGHIERI, 2008, p. 179).

${ }^{3}$ A expectativa de que o leitor/ouvinte compreenda a mensagem por trás dos versos do poema está também em Dante, Inferno, Canto IX: O voi ch'avete li 'ntelletti sani,/mirate la dottrina che s'asconde/sotto ' 1 velame de li versi strani. (ALIGHIERI, 2012, p. 282-283). [Ó intelectos sadios e judiciosos,/entendei a doutrina disfarçada/sob o velame dos versos curiosos! Trad. Ítalo Eugenio Mauro. (ALIGHIERI, 2008, p. 75)].
} 
Pikolo me pede para repetir esses versos. Como ele é bom: compreendeu que está me ajudando. Ou talvez seja algo mais: talvez (apesar da tradução pobre e do comentário banal e apressado) tenha recebido a mensagem, percebido que se refere a ele também, refere-se a todos os homens que sofrem e, especialmente, a nós: a nós dois, nós que ousamos discutir sobre estas coisas, enquanto levamos nos ombros as alças do rancho (LEVI, 1988, p.116).

No verso que Levi pede que Jean compreenda, Dante recorre à noção judaico-cristã da origem divina do homem ("considerai a vossa procedência") e o eleva. O homem foi feito à imagem e semelhança de Deus, não pode ser confundido com um bicho. Sua estirpe é outra, e pelo seu intelecto deve buscar virtude e conhecimento. Essas palavras possuem tal força na mente do prisioneiro italiano que o fazem sentir-se mais humano, apesar de todo o esforço do regime nazista em fazer o contrário. Ao cumprir com seu papel humanizador, a literatura o salva. Não da morte física, mas da morte espiritual, da desumanização, do mergulho no abismo. A literatura confirma no prisioneiro a sua condição de homem:

Justamente porque o Campo é uma grande engrenagem para nos transformar em animais, não devemos nos transformar em animais; até num lugar como este, podese sobreviver, para relatar a verdade, para dar nosso depoimento; e, para viver, é essencial esforçar-nos por salvar ao menos a estrutura, a forma da civilização (LEVI, 1988, p. 55).

Ao contrário do inferno dantesco, que segue uma ordem divina, uma lei do contrapasso em que as penas são aplicadas na medida do pecado cometido, o inferno de Levi não parece obedecer a qualquer lógica. O sentimento das vítimas é de perplexidade diante dos acontecimentos: "de que deveríamos nos arrepender ou ser perdoados?" (LEVI, 1988, p. 13); "Lá recebemos as primeiras pancadas, o que foi tão novo e absurdo que não chegamos a sentir dor, nem no corpo nem na alma. Apenas um profundo assombro: como é que, sem raiva, pode-se bater numa criatura humana?"(LEVI, 1988, p. 15). Mas ao lembrar-se dos versos em que Ulisses narra a violência do mar que resultou no trágico naufrágio ${ }^{4}$, Levi parece ter uma epifania:

Seguro Pikolo, é absurdamente necessário e urgente que escute, que compreenda o que significa esse 'come altrui piacque', antes que seja tarde demais: amanhã, ou ele ou eu poderemos estar mortos ou não nos rever nunca mais, devo falar-lhe, explicarlhe [...] algo grandioso que acabo de ver, agora mesmo, na intuição de um instante, talvez o porquê do nosso destino, do nosso estar aqui, hoje... (LEVI, 1988, p. 117)

A interpretação de Levi do verso de Dante "come altrui piacque" (como a alguém agradou) é o trecho mais polêmico e obscuro do livro e, ainda assim, parece ser uma revelação de grande valor. Uma tentativa de explicar o horror do campo por um plano divino, como se houvesse uma vontade suprema que servisse para dar esperança aos prisioneiros, que pudesse acalmar o assombro e a falta de sentido daquela experiência. Eles não estavam abandonados ao caos e à vontade de um único homem, mas seguiam uma lógica divina insondável.

\section{Literatura e promoção dos direitos humanos}

No Direito à literatura Candido afirma que, além da organização dos sentimentos e da visão de mundo, a literatura promove um diálogo direto com os direitos humanos pelos

4 "Tre volte il fé girar con tutte l'acque; a la quarta levar la poppa in suso/ e la prora ire in giù, com'altrui piacque". (ALIGHIERI, 2012, p. 792). [Três vezes, co' a água toda, ele rodou;/na quarta, erguida a popa, foi arrojado,/proa abaixo, como a alguém agradou. Trad. Italo Eugenio Mauro (ALIGHIERI, 2008, p. 180)]. 
conhecimentos intencionais que ela transmite, quando deixa claras as posições políticas e humanitárias de seu autor. É o caso da literatura empenhada que carrega consigo uma mensagem de ideologia, de revolta ou de denúncia. A eficácia da mensagem literária, no entanto, depende da construção feita pelo artista, do modo de organização das representações mentais. É justamente a forma o que diferencia um narrador empenhado de um militante.

No texto Literatura e formação do homem, o crítico brasileiro diz que, ao analisar uma obra literária, há um momento de concentração no texto como objeto artístico e há também um momento crítico, de compreensão da função da obra como "síntese e projeção da experiência humana" (CANDIDO, 2002, p. 82). Cabe-nos entender, portanto, como a obra de Levi contribui para a promoção dos direitos humanos, a partir de sua estrutura e de sua função.

No que se refere à forma, nota-se claramente duas coisas. A primeira delas é o uso constante da primeira pessoa do plural, nós, o que faz com que o autor deixe de se concentrar demasiadamente em sua dor e se colocar como centro da narração. Levi é um sobrevivente, mas seu testemunho quer falar por todos aqueles que não tiveram a mesma chance, constituindo o que Lucie Benchouiha chama de multiple testimony (BENCHOUIHA, 2006, p. 7): "nós éramos apenas exemplares comuns da espécie humana"; "sofríamos com a sede e o frio"; "bem sei que, contando isso, dificilmente seremos compreendidos"; "roubarão também o nosso nome, e, se quisermos mantê-lo, deveremos encontrar dentro de nós a força para tanto, para que, além do nome, sobre alguma coisa de nós, do que éramos".

Um segundo aspecto a ser notado na forma é a opção por uma linguagem direta e enxuta, livre de qualquer excesso. A serenidade do tom e a lucidez das observações, no entanto, contrastam de maneira evidente com o sofrimento extremo e as inúmeras privações narradas no texto. Enquanto sofre todo tipo de tortura e opressão, Levi não abandona sua posição de observador agudo, demonstrando uma capacidade de distanciamento e de análise extraordinária. O que justifica esse contraste entre forma e conteúdo e resolve a contradição é, para usar um termo de Antonio Candido, o princípio organizador da obra, que nesse caso é a própria resistência. Candido afirma que:

\footnotetext{
A literatura é essencialmente uma reorganização do mundo em termos de arte; a tarefa do escritor de ficção é construir um sistema arbitrário de objetos, atos, ocorrências, sentimentos, representados ficcionalmente conforme um princípio de organização adequado à situação literária dada, que mantém a estrutura da obra. (CANDIDO, 2006 p. 186)
}

Assim, a resistência pode ser considerada o princípio de organização do texto quando Levi recusa a tradição clássica e romântica de que estava impregnada a Europa e se contrapõe, com sua linguagem clara e simples, suas frases breves, a uma retórica e uma estética magniloquentes caras aos regimes totalitários. Por outro lado, à ameaça de silêncio e esterilidade do hermetismo, Levi prefere a comunicabilidade. Em um ensaio intitulado Dello scrivere oscuro, publicado na coletânea L'altrui mestiere (1985), Levi defende que o valor de um texto reside na sua capacidade de ser compreendido. Para o escritor italiano, não há nada de revolucionário na escrita obscura, mas sim um artifício repressivo, bastante comum na classe política. $\mathrm{O}$ autor ainda compara a escrita obscura a um gemido de dor, ou a um grito no deserto: ainda que seja benéfico como alívio da tensão e desabafo, não possui articulação, não é linguagem. O exprimível é preferível ao inefável, e a palavra humana ao ganido animal (LEVI, 2009, p. 52).

O inferno, assim como o campo de concentração, é o lugar da não-comunicação. $O$ lugar em que os gritos e lamentos sobrepõem-se à palavra humana. Lembremos, a esse respeito, dos demônios Pluto e Nimrod, na Divina Comédia, relegados ao solipsismo com suas linguagens incompreensíveis, até a privação completa da palavra em Lúcifer. E ainda, as 
palavras de Virgílio sobre a fala confusa de Nimrod: "Lasciamlo stare e non parliamo a voto;/ché così è a lui ciascun linguaggio/ come ' 1 suo ad altrui, ch'a nullo è noto" (ALIGHIERI, 2012, p. 927).

De modo semelhante, no Lager, que concentra homens de diversas nacionalidades, a língua se "esvai em poucos dias e, com a língua, o pensamento" (LEVI, 1990, p. 54). A resistência ao desaparecimento da própria língua se une à necessidade de se adaptar ao ambiente multilíngue em que se encontra. Não compreender um comando em alemão, por exemplo, representaria um grande risco à própria sobrevivência. Assim, Levi esforça-se por conseguir se comunicar em meio às "inflexões de todas as línguas da Europa" (LEVI, 1988, p. 178) e mais de uma vez recorre à metáfora da Babel bíblica para descrever o campo:

\begin{abstract}
A Torre do Carbureto, que se eleva no meio da fábrica e cujo topo raramente se enxerga na bruma, fomos nós que a construímos. Seus tijolos foram chamados ziegel, briques, tegula, cegli, kamenny, bricks, téglak, e foi o ódio que os cimentou; o ódio e a discórdia, como a Torre de Babel, e assim a chamamos: Babelturm, Babelturm, e odiamos nela o sonho demente de grandeza de nossos patrões, seu desprezo de Deus e dos homens, de nós, homens. E, ainda uma vez, hoje, como na antiga lenda, nós todos percebemos (e os mesmos alemães o percebem) que uma maldição - não transcendente e divina, mas imanente e histórica - pende sobre essa insolente estrutura, fundada na confusão das linguagens e erguida a desafiar o céu, como uma blasfêmia de pedra. (LEVI, 1988, p. 73)
\end{abstract}

Por ter vivido essa experiência, para Levi comunicar é um imperativo ético e um compromisso que se revela em seu estilo. Traduzir em palavras humanas uma experiência inumana, esse é o desafio do escritor que se coloca como testemunha de uma das maiores catástrofes da humanidade.

\title{
4. Considerações finais
}

Nas diversas entrevistas que concedeu quando já havia se tornado um escritor de sucesso, Levi deixa claro que, para ele, o sentido de sua sobrevivência está na escrita. Testemunhar não é uma escolha, mas um dever para com os companheiros que não sobreviveram. Além disso, o escritor italiano afirma, no capítulo Os submersos e os salvos, que toda experiência humana é portadora de um sentido e que também da experiência do campo podem-se extrair valores fundamentais.

A necessidade de testemunhar, no entanto, esbarra na dificuldade de colocar em palavras o trauma vivido:

Assim como nossa fome não é apenas a sensação de quem deixou de almoçar, nossa maneira de termos frio mereceria uma denominação específica. Dizemos 'fome', dizemos 'cansaço', 'medo' e 'dor', dizemos 'inverno', mas trata-se de outras coisas. Aquelas são palavras livres, criadas, usadas por homens livres que viviam, entre alegrias e tristezas, em suas casas. Se os Campos de Extermínio tivessem durado mais tempo, teria nascido uma nova, áspera linguagem, e ela nos faz falta agora para explicar o que significa labutar o dia inteiro no vento, abaixo de zero, vestindo apenas camisa, cuecas, casaco e calças de brim e tendo dentro de si fraqueza, fome e a consciência da morte que chega (LEVI, 1988, p. 125-126)

Esse paradoxo do testemunho, no entanto, não significa a impossibilidade de transmissão de uma mensagem, de um diálogo direto da literatura com os direitos humanos. Para o filósofo italiano Giorgio Agamben, negar a possibilidade do testemunho é compactuar com o projeto nazista:

\footnotetext{
${ }^{5}$ Larguemos dele e de prosa perdida,/porque pra ele é assim qualquer linguagem/qual pra outrem é a sua, desconhecida. Trad. Italo Eugenio Mauro. (ALIGHIERI, 2008, p. 208).
} 
Os que reivindicam, hoje, a impossibilidade de dizer Auschwitz, deveriam ter cautela nas afirmações. [...] Se, conjugando 'unicidade' e 'indizibilidade', fazem de Auschwitz uma realidade absolutamente separada da linguagem, se cortam, no 'muçulmano ${ }^{6}$, a relação entre impossibilidade e possibilidade de dizer que constitui o testemunho, então eles repetem inconscientemente o gesto dos nazistas, são secretamente solidários com o 'arcanum imperii' (AGAMBEN, 2008, p. 156)

A obra de Levi mostra-se um instrumento privilegiado de denúncia e de combate às violações dos direitos humanos em um momento em que parte das pessoas procura esquecer, senão negar, este passado desolador. O sentido de seu texto não consiste somente em descrever a experiência do campo como um acidente do passado, mas em alertar as novas gerações sobre o poder do Estado moderno e o perigo que se mantém na sociedade contemporânea, mesmo após a queda do nazifascismo. Giorgio Agamben, afirma que, ao analisar a estrutura jurídico-política do campo, podemos entendê-lo não como uma anomalia do passado, mas como "matriz oculta, o nómos do espaço político que ainda vivemos" (AGAMBEN, 2002, p. 173). O testemunho de Levi rebate a utopia da força civilizadora do Estado e atenta para o fato de que o saber, o progresso e a ciência podem caminhar ao lado da barbárie.

\section{Referências}

Agamben, Giorgio. Homo sacer: o poder soberano e a vida nua. Tradução de Henrique Burigo. Belo Horizonte: Editora da UFMG, 2002.

Agamben, Giorgio. O que resta de Auschwitz: o arquivo e a testemunha (Homo Sacer III). Tradução de Selvino J. Assmann. São Paulo: Boitempo, 2008.

Alighieri, Dante. La Divina Commedia. Milano: Mondadori, 2012.

Alighieri, Dante. A Divina Comédia. Tradução de Italo Eugenio Mauro. São Paulo: Editora 34, 2008.

Benchouiha, Lucie. Primo Levi: Rewriting the Holocaust. Leicester: Troubador, 2006.

Bosi, Alfredo. "A escrita do testemunho em Memórias do Cárcere”. In: Bosi, Alfredo. Literatura e Resistência. São Paulo: Companhia das Letras, 2002.

Candido, Antonio. “Livros”. Clima. n.1. São Paulo: maio de 1941a.

Candido, Antonio. "Livros". Clima. n.4. São Paulo: setembro de 1941b.

Candido, Antonio. "O direito à literatura". In: Candido, Antonio. Vários escritos. 3.ed. São Paulo: Duas Cidades/Ouro sobre Azul, 1995.

Candido, Antonio. “A literatura e a formação do homem”. In: Candido, Antonio. Textos de Intervenção. São Paulo: Duas Cidades/Editora 34, 2002.

\footnotetext{
6 "Muçulmano" era o termo usado nos campos de concentração para se referir àqueles que já tinham esgotado suas forças e estavam prestes a morrer.
} 
Candido, Antonio. Literatura e Sociedade. São Paulo: Ouro Sobre Azul, 2006.

Cereja, Federico. "La testimonianza di Primo Levi come documento di storia". Rassegna Mensile Israel, [s.1], vol. 55, n 2-3, maio-dezembro, 1989.

Levi, Primo. É isto um homem?. Tradução de Luigi Del Re. Rio de Janeiro: Rocco, 1988.

Levi, Primo. Os afogados e os sobreviventes Tradução de Luiz Sérgio Henriques. Rio de Janeiro: Paz e Terra, 1990.

Levi, Primo. "Dello scrivere oscuro". In: Levi, Primo. L'altrui mestiere. Torino: Einaudi, 2009.

Recebido em: 24 de julho de 2019 Aceito em: 07 de novembro de 2019

Publicado em: Dezembro de 2019 